\title{
Monitoring the Spectrum of Donor Deferrals in a Hospital Blood Bank: A Tertiary care Hospital Experience
}

Attika Khalid*, Nazia Khalid and Madeeha Rehan

Department of Hematology, Foundation University Medical College/Fauji Foundation Hospital, Islamabad, Pakistan

\begin{abstract}
Introduction: In an ever-rising need of blood and blood products, donor deferrals not only dent the existing donor pool but also reduces the possibility of further donation by the potential blood donor. This study aims to get an insight into the frequency and causes of deferrals in the region.
\end{abstract}

Methods: This retrospective study was conducted in the blood bank of Fauji Foundation Hospital, Rawalpindi. Al the potential donors were evaluated on the basis of clinical history, physical examination and Blood count estimation. Blood was collected from the donors that are deemed fit by above criteria and was screened for Malaria, hepatitis $\mathrm{B}, \mathrm{C}, \mathrm{HIV}$ and syphilis.

Results: Out of the total 4225 potential donors $26(0.61 \%)$ were females, $1988(47 \%)$ were in the age range $15-30$ years. Of the total potential donors $9.7 \%$ donors (410) were deferred. Amongst the deferred, $64 \%$ were deferred pre-donation during initial history taking and examination. Amongst the pre-donation deferrals the most common cause was anemia $(52.4 \%)$ followed by leukocytosis $(19.7 \%)$ and thrombocytopenia $(4.8 \%)$ respectively. Post donation deferrals included those patients who showed seropositivity to either hepatitis B, C, HIV, malaria or syphilis. It comprised of $34 \%$ of the total deferrals. Hepatitis B was the most common cause of post donation deferral comprising about $49.6 \%$ followed by hepatitis C (46\%). Only 05 HIV positive cases reported.

Conclusion: The analysis of rate and causes of donor deferral may help not only in preventing the donor loss but also in initiating the recruitment efforts and establishing general awareness campaign regarding safety and benefits of donation process at a mass level to help mobilizing voluntary donors from both genders.

Keywords: Blood transfusion; Hemoglobin; Population; Blood

\section{Introduction}

Blood transfusion practices are considered a vital lifesaving procedure $[1,2]$. They are widely demanded in various medical and surgical conditions most commonly to treat anemia or blood loss secondary to any condition [1-3]. Owing to increasing life expectancy and health awareness, it has become Back bone of a patient's management in today's health care system [4]. In countries like Pakistan, with the population of over 180 million and a huge burden of disease including many transfusion dependent conditions such as thalassemia, a ready source of blood and its components is a dire need $[2,5]$. The demand of blood is always outpacing the supply or the stock in blood banks [6]. As this vital health care resource has no complete substitute till date [7], therefore it has become necessary to have an adequate supply of safe blood from a healthy donor [2]. The sources of donated blood are replacement donors that donate blood as a replacement for their relative's or friend's needs, voluntary unpaid donors, and paid donors [8]. Lacking a proper donor base system as well as awareness in Pakistan, the main source always remain the replacement donors [5]. The World Health Organization recommends a collection rate of 10-20 whole blood units per 1000 population whereas in a survey also conducted by W.H.O. [9] over 81 million units of blood are collected annually worldwide out of which only $39 \%$ are collected in developing countries which have $82 \%$ of the world's population [1,9]. A discouraging trend is generally observed regarding donating blood because of various myths that a Pakistani society holds [10-12]. The scarce number of donors which may themselves perceive to be healthy may be unfit or unsuitable for blood donations and therefore may be deferred [13]. These deferrals may be temporary or permanent depending upon health and life style conditions [13-15]. Mostly deferred pre donation but some are also deferred for various time period post donation upon screening. The most common deferral reported is due to a low hemoglobin concentration, affecting around $5 \%$ of donors each year $[15,16]$. Deferrals lead to loss of precious blood/components available for transfusion [1]. Furthermore temporary deferrals may also reduce the probability of further donation by the potential blood donor $[17,18]$.

For preventing this and to avoid the disparity in supply and demand, a careful evaluation and knowledge of causes and frequency of deferrals; both pre and post donation is required [12]. A better understanding of the reasons and rates of donor deferral is very important so as to avoid the permanent loss of the donor. Since blood donation program is the life force of any blood bank and hospital this study aims to assess causes of donor deferrals in our set up and give an insight into the current practices in our health system. Furthermore, it may help in future improvement in recruitment and awareness plans at mass level to establish a larger and healthier donor pool [14].

\section{Material and Methods}

\section{Study setting}

This retrospective study included all the donors from both genders reporting for blood donation in the blood bank of Fauji Foundation Hospital, Rawalpindi from 1 ${ }^{\text {st }}$ October 2016 to 31st March 2017.

${ }^{*}$ Corresponding author: Attika Khalid, Department of Hematology, Foundation University Medical College/Fauji Foundation Hospital, Defence Housing Authority (DHA) PHASE 1, Islamabad, Pakistan; E-mail: aatika.khalid@gmail.com

Received March 21, 2018; Accepted April 02, 2018; Published April 11, 2018

Citation: Khalid A, Khalid N, Rehan M (2018) Monitoring the Spectrum of Donor Deferrals in a Hospital Blood Bank: A Tertiary care Hospital Experience. J Blood Lymph 8: 214. doi:10.4172/2165-7831.1000214

Copyright: ( $) 2018$ Khalid A, et al. This is an open-access article distributed unde the terms of the Creative Commons Attribution License, which permits unrestricted use, distribution, and reproduction in any medium, provided the original author and source are credited. 


\section{Donor recruitment criteria}

The study included both replacement as well as voluntary donors. The donors were initially evaluated on the basis of clinical history and physical examination. Blood count estimation (Hemoglobin, total leukocyte count and platelet count) is done as next step. This is performed on $\mathrm{CBC}$ analyzer sysmex Xn-1000. If the prospective donor does not fit the donor criteria they are deferred prior to blood donation. W.H.O guidelines for blood donor deferral was applied [19].

\section{Screening for infections}

Blood was collected from the donors that are deemed fit by above criteria. The blood sample was subjected to screening for Malaria, hepatitis B, C and HIV. Hepatitis B surface antigen detection and antibody to hepatitis $\mathrm{C}$ and both HIV 1 and 2 were performed on Elisa third generation, while malaria was detected through immunochromatographic techniques on binaxnow ICT kit. Blood found positive in screening was discarded post donation and the donor was informed and counseled about the diagnosis. A physician consultation is also suggested to the deferred donor.

\section{Data analysis}

The data were entered and analyzed by using SPSS version 17 . The mean and standard deviation was calculated for all the parametric variables and the causes for deferrals were expressed in percentage.

\section{Results}

A total of 4225 potential donors reported in our blood bank during the study period. Most of the donors were replacement donors while only a small fraction of $0.26 \%$ ( 11 donors) were voluntary donors. Females constituted a very small fraction of the potentials donors .26 potential donors were females whereas 4199 were males. The clinical characteristics of the potential blood donors are shown in Table 1. Out of the total 4225 donors $9.68 \%$ donors (410) were deferred during various stages of donation (Figure 1). Amongst the deferred, $64 \%$ were deferred pre-donation during initial history taking and examination. There was a minor fraction of the total donations, $0.15 \%$ who were deferred despite deemed fit clinically as well as on laboratory parameters. These deferrals were made during phlebotomy process mostly in the initial phase due to sweating, palpitation and black outs. Amongst the pre-donation deferrals the most common cause was anemia (low hemoglobin values) followed by leukocytosis and thrombocytopenia respectively. The causes of pre-donation deferral are shown in Table 2. Post donation deferrals included those patients who showed seropositivity to either hepatitis B, C or HIV in the screening process. It comprised of $34 \%$ of the total deferrals. Deferral due to seropositivity was mostly seen due to hepatitis b comprising about $49.6 \%$ of total post donation deferrals (Table 3).

\section{Discussion}

The overall deferral rate in our study is found to be $9.68 \%$. Various studies conducted locally, regionally and internationally shows varied rate of deferral of the potential donors. From as low as $4-6 \%$ in various studies conducted in different parts of India [20-22] to as high as 35.6\% [23]. This is owing to variation in health standards, health resources, and awareness in the population and also by the criteria selected for deferring the prospective donors. A significant proportion of high risk sexual activities may have caused a higher deferral rate in Trinidad and Tobago $\mathrm{D}$ which is relatively uncommon in our region owing to different religious and social practices [23]. This is also supported by the various other studies conducted in Pakistan that depicts deferral rate of $10-12 \%$ which is similar to our study $[8,24,25]$. Maxime Diane Kouao showed a deferral rate of $10.74 \%$ [9] while Bobati et al. [26] showed a deferral of $8.62 \%$ all conforming to our study.

Most studies conducted locally as well as internationally show a

\begin{tabular}{|c|c|c|c|c|c|c|}
\hline Gender & $\begin{array}{c}\text { Donors } \\
\text { (percentage) }\end{array}$ & Voluntary & Involuntary donors & $\begin{array}{c}\text { Age range } \\
(15-30)\end{array}$ & $\begin{array}{c}\text { Age range } \\
(31-45)\end{array}$ & $\begin{array}{c}\text { Age range } \\
(46-60)\end{array}$ \\
\hline Male & $\begin{array}{c}4199 \\
(99.3 \%)\end{array}$ & 8 & 4191 & 1972 & 1678 & 549 \\
\hline \multirow[t]{2}{*}{ female } & $\begin{array}{c}26 \\
(0.61)\end{array}$ & 3 & 23 & 17 & 09 & 0 \\
\hline & $\begin{array}{c}4225 \\
(100 \%)\end{array}$ & $\begin{array}{c}11 \\
(0.26 \%)\end{array}$ & $\begin{array}{c}4214 \\
(99.7 \%)\end{array}$ & $\begin{array}{c}1989 \\
(47 \%)\end{array}$ & $\begin{array}{c}1687 \\
(39.7 \%)\end{array}$ & $\begin{array}{c}549 \\
(12.99 \%)\end{array}$ \\
\hline
\end{tabular}

Table 1: Clinical characteristics of potential blood donors.

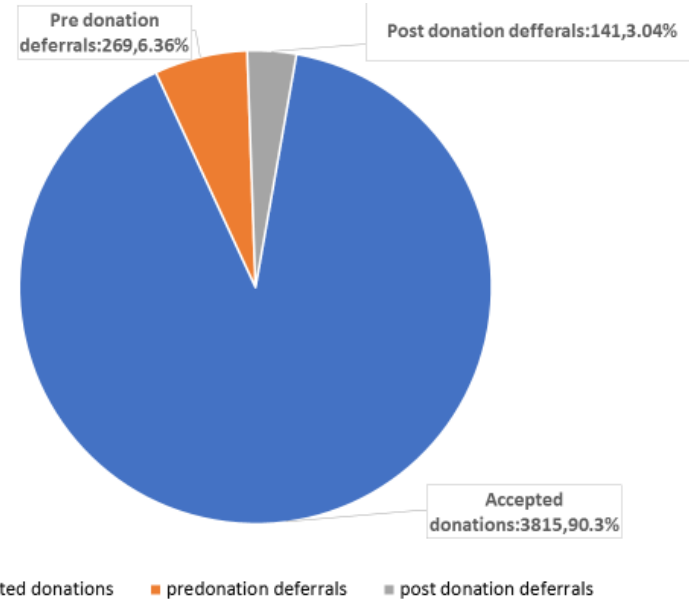

Figure 1: Spectrum of pre and post donation deferrals 


\begin{tabular}{|l|c|c|}
\hline Pre -donation deferrals & Total count 269 & Percentage \\
\hline Low hemoglobin & 141 & $52.4 \%$ \\
\hline High TLC & 53 & $19.7 \%$ \\
\hline thrombocytopenia & 13 & $4.8 \%$ \\
\hline $\begin{array}{l}\text { Within three months of previous } \\
\text { donation }\end{array}$ & 10 & $3.7 \%$ \\
\hline Anxiety & 7 & $2.6 \%$ \\
\hline Under weight & 7 & $2.6 \%$ \\
\hline Miscellaneous & 6 & $2.2 \%$ \\
\hline On antibiotics & 5 & $1.9 \%$ \\
\hline Fever & 4 & $1.5 \%$ \\
\hline High hemoglobin & 4 & $1.5 \%$ \\
\hline Diabetes on insulin & 4 & $1.5 \%$ \\
\hline Under age & 3 & $1.1 \%$ \\
\hline Asthma & 3 & $1.1 \%$ \\
\hline Low TLC & 2 & $0.7 \%$ \\
\hline Menstruation & 2 & $0.7 \%$ \\
\hline High blood pressure & 2 & $0.7 \%$ \\
\hline Cardiovascular disease & 1 & $0.4 \%$ \\
\hline Pregnancy & 1 & $0.4 \%$ \\
\hline Jaundice & 1 & $0.4 \%$ \\
\hline
\end{tabular}

Table 2: Pre-donation deferral causes in study population.

\begin{tabular}{|l|c|c|}
\hline Post donation deferrals & Total count $\mathbf{1 4 1}$ & Percentage \\
\hline Hepatitis B & 70 & 49.6 \\
\hline Hepatitis C & 66 & 46 \\
\hline HIV & 5 & 3.54 \\
\hline Malaria & 0 & 0 \\
\hline
\end{tabular}

Table 3: Post donation deferral; causes and percentage in the study population.

lesser frequency of females in potential donor pool in congruence with our study $[1,3,4,27]$. It has been suggested that fear of some of blood collection process that includes needles or feeling unwell contributes to the lack of female donors globally. This paucity of female donors in our set up may also be due to social practices and myths prevailing in our society that females cannot donate. It calls for awareness amongst the population to encourage donations at a mass level.

The most common cause of deferral amongst both gender in our study has been low hemoglobin values followed by high TLC and thrombocytopenia. Low hemoglobin value is reported to be the most common cause in most of the studies all over the world as well $[1,2,8,24]$. This is even more in our country that reflects the strained economics and health care system of our country. Ekwere et al. [13] in his study reported that the most common cause over all was transfusion transmitted infections amongst which most cases were HIV positive. $\mathrm{HIV}$ and Aids is otherwise a common and major health problem in Nigeria [28] leading therefore to larger number of potential donors with HIV positivity in their region. Similarly, another study by Charles et al. [23] conducted in Trinidad and Tobago showed high risk sexual activities to be the leading cause of deferral. Maxime Diane Kouao et al. [9] reported change in sexual partners whereas Bobati et al. [24] rated alcohol consumption as the second most common cause. No case of alcohol or high risk sexual activity is reported in our study as well. Contrary to this, HIV forms only a small fraction of deferral cases in our study. This is most likely due to different social and religious practices in our country. Another reason may be the under reporting of such activities as it is a socially unacceptable practice in the prevalent society. To minimize donations from high risk group, we provide literature to donors even before registration, regarding causes that could lead to deferrals so that if they fell themselves not fit for donation they themselves refrain from donation. Shahtaj et al.
[14] reported hypotension to be the most common cause followed by anemia. Another study conducted locally reports $5 \%$ cases of deferrals due to hypotension [29]. A higher proportion of deferrals due to hypotension $[30,31]$, however, stated hypertension as the most common over all cause of deferral. It is contrary to our study where no cases of hypotension were reported whereas only two deferrals due to hypertension were reported. Hypertension is not reported in higher frequencies in many other local and international studies as well $[8,32]$. This may be due to the difference in the awareness of the population coming for donation and also by the counseling and reassurance by the blood bank staff. All the potential donors are advised to have a healthy breakfast on the day of donation. Furthermore, most donations are carried out in the morning hours leading to a possible reduction of hypotension as a cause of rejection. Hypertension could be due to fears of phlebotomy, white-coat hypertension, exercise, stress, etc. These issues can be catered with a good pre-donation counselling and reassurance. Similarly owing to the larger family sizes, replacement donors that are deemed apparently healthy by the family are sent for donation therefore factors like hypertension, known hepatitis cases or chronic diseases and surgical causes are eliminated automatically. Rehman et al. [24] reports malaria as the second most common cause in his study. Although the endemicity of our region is similar to where the study was conducted, this difference may be attributed to the seasonal difference in malaria infection observed with less likely cases reported in autumn-winters, the prime time in which our study was conducted.

Leukocytosis i.e., high total leucocyte count is rated as the second most common cause in our study. Similar findings are reported in a local study by Nadeem [32]. While it is not mentioned in some studies as a significant cause $[8,30]$. Owing to the poor environmental and hygienic conditions in our country non-specific underlying infective processes are common and general population do not tend to report sore throats or mild cough with fever as significant problem. These underlying infections may have caused leukocytosis that has led to a deferral in our study.

The role of care managers could be significant in the area of recruiting donors and increasing awareness regarding avoidable causes of donor deferral. To the best of knowledge, no other study locally or internationally as yet has determined the role of care managers in this area. This study has been limited in determining the role of care managers. The reason being the under developed and resource constraint health system in the region [33].

\section{Limitations}

The study is based on a single center data and therefore results cannot be taken as broadly representative of the general population. Moreover, being a retrospective study there is limitation of availability of complete relevant data.

\section{Future Direction}

There is a need to re-orientate our awareness, recruitment and retention strategies in order to maintain adequate safe blood supply. Further research on broader scale is needed regarding preventable causes of donations, awareness levels to enhance the donor pool.

\section{Conclusion}

The analysis of rate and causes of donor deferral in specific demographic areas can help in developing a safe blood donor pool It will also help in increasing awareness amongst the temporary deferred donors and motivate them for future donations. Addressing 
Citation: Khalid A, Khalid N, Rehan M (2018) Monitoring the Spectrum of Donor Deferrals in a Hospital Blood Bank: A Tertiary care Hospital Experience. J Blood Lymph 8: 214. doi:10.4172/2165-7831.1000214

common issues like anemia and infective causes by their treatment and prevention could help regain the donors and assist in developing a healthy and large donor base. Similarly, a general awareness campaign regarding safety and benefits of donation process at a mass level can help in mobilizing voluntary donors of both genders

\section{Funding Resource}

This research did not receive any specific grant from funding agencies in the public, commercial, or not-for-profit sectors.

\section{References}

1. Yaddanapudi S, Yaddanapudi $L$ (2014) Indications for blood and blood product transfusion. Indian J Anaesth 58: 538-542.

2. Rehman S, Arif SH, Mehdi G, Mirza S, Saeed N, et al. (2012) The Evaluation of Blood Donor Deferral Causes: A Tertiary Care Centre-based Study. J Blood Disorders Transf 3: 131.

3. Walter DH (2015) Innocent lives lost and saved: the importance of blood transfusion for children in sub-Saharan Africa. BMC Medicine 13: 22.

4. Far RM, Rad FS, Abdolazimi Z, Kohan MMD (2014) Determination of Rate and Causes of Wastage of Blood and Blood Products in Iranian Hospitals. Turk J Haematol 31: 161-167.

5. Zaheer HA, Waheed U (2014) Blood safety system reforms in Pakistan. Blood Transfus 12: 452-457.

6. Sharma N, Kaushik S, Kumar R, Azad S, Acharya S, et al. (2014) Causes of Wastage of Blood and Blood Components: A Retrospective Analysis. IOSR J of Evidence Based Med \& Hlthcare (IOSR-JDMS) 13: 59-61.

7. Bobde V, Parate S, Kumbhalkar D (2015) Analysis of Discard of Whole Blood and Blood Components in Government Hospital Blood Bank in Central India. J of Evidence Based Med \& Hlthcare 2: 1215-1220.

8. Tufail S, Babar F, Ikram N, Raza M, Shakoor AH (2013) Blood Donors DeferralCauses. J Rawal Med Coll 17: 119-121.

9. Kouao MD, Dembelé B, N'Goran LK, Konaté S, Bloch E, et al. (2012) Reasons for blood donation deferral in sub-Saharan Africa: experience in Ivory Coast. Transfusion 52: 1602-1606

10. Greinacher A, Fendrich K, Brzenska R, Kiefel V, Hoffmann W (2011) Implications of demographics on futureblood supply: a population-based crosssectional study. Transfusion 51: 702-709.

11. Mumtaz Z, Bowen S, Mumtaz R (2012) Meanings of blood, bleeding and blood donations in Pakistan: implications for national vs global safe blood supply policies. Health Policy Plan 27: 147-155.

12. Ngoma AM, Goto A, Nollet KE, Sawamura Y, Ohto H, et al. (2014) Blood Donor Deferral among Students in Northern Japan: Challenges Ahead. Transfus Med Hemother 41: 251-256.

13. Ekwere TA, Ino-Ekanem M, Motilewa OO, Ibanga IA (2014) Pattern of blood donor deferral in tertiary hospital, South-south, Nigeria:A three-year study review. Int J Blood Tranfus Immuno Hematol 4: 7-12.

14. Khan S, Rehman N, Raziq F (2012) Donor Deferral: Evaluation of Causes on Pre-Donor Screening. Gomal J Med Sci 10: 23-26.

15. Hillgrove TL, Doherty KV, Moore VM(2012) Understanding non-return after temporary deferral from giving blood: A qualitative study. BMC Public Health 12: 1063.
16. Hillgrove $T$, Moore V, Doherty $K$, Ryan $P$ (2011) The impact of temporary deferral due to low hemoglobin: future return, time to return, and frequency of subsequent donation. Transfusion 51: 539-547.

17. Zou S, Musavi F, Notari EP, Rios JA, Trouern-TrendJ, Fang CT (2008) Dono deferral and resulting loss at theAmerican Red Cross Blood Services, 2001 through2006. Transfusion 48: 2531-2539.

18. Custer B, Chinn A, Hirschler NV, Busch MP, Murphy EL (2014) The consequences of temporary deferral on future whole blood donation. Transfus Med Hemother 41: 251-256.

19. World Health Organization (2012) Blood Donor Selection: Guidelines on Assessing Donor Suitability for Blood Donation. Geneva: World Health Organization.

20. Unnikrishnan B, Rao P, Kumar N, GantiS, Prasad R, et al (2011) Profile of blood donors and reasonsfor deferral in coastal South India. Australas Med $J$ 4: 379-385.

21. Sundar P, Sangeetha SK, Seema DM, Marimuthu P, Shivanna N (2010) Predonation deferral of blood donors in South Indian set-up: An analysis. Asian J Transfus Sci 4: 112-115

22. Rabeya Y, Rapiaah M, Rosline H, Ahmed SA, Zaidah WA, et al. (2008) Blood pre-donation deferrals-a teaching hospital experience.Southeast Asian J Trop Med Public Health 39: 571-574.

23. Charles KS, Hughes P, Gadd R, Bodkyn CJ, Rodriguez M (2010) Evaluation of blood donor deferral causes in the Trinidad and Tobago National Blood Transfusion Service. Transfus Med 20: 11-14.

24. Rehman MU, Akhtar GN, Qadeer M (2003) Safe blood begins with safe donors Pak J Med Sci 19: 161-68.

25. Ali N, Nadeem M, Qamar A, Qureshi AH, Ejaz A (2003) Frequency of Hepatitis $C$ virus antibodies in blood donors in combined military hospital Quetta. Pak Med Sci 19: 41-44.

26. Bobati SS, Basavraj V, Prakash P (2016) Analysis of predonation loss of blood donors due to deferrals- in a tertiary care hospital set up. Int $\mathrm{J}$ Health Allied Sci 5: 15-18

27. Mangwana S (2013) Analysis of blood donor deferral pattern: Scenario in a Tertiary Health Care Hospital in India. Asian J Transfus Sci 7: 160-161.

28. Monjok E, Smesny A, Essien EJ (2009) HIV/AIDS-Related Stigma and Discrimination in Nigeria: Review of Research Studies and future directions for Prevention Strategies. Afr J Reprod Health 13: 21-35.

29. Waheed U, Zaheer HA (2016) Evaluation of deferral pattern among the blood donors in Islamabad, Pakistan. Glob J Transfus Med 1: 81-84.

30. Abdelaal M, Anwar F (2016) Analysis of blood donor deferral in Jeddah, Saudi Arabia: Characteristics and causes. J Pak Med Assoc 66: 1392-1395.

31. John F, Varkey MR (2015) Evaluation of blood donor deferral causes in a tertiary hospital, South India. Int J of Biomed and Adv 6: 253-258.

32. Nadeem A, Salamat N, Iqbal N, Siddique N, Ejaz U, et al. (2016) Demographic features of donors and causes of blood donor deferral at armed institute of transfusion, Rawalpindi. Pak Armed Forces Med J 66: 898-902.

33. Ciccone MM, Aquilino A, Cortese F, Scicchitano P, Sassara M, et al. (2010) Feasibility and effectiveness of a disease and care management model in the primary health care system for patients with heart failure and diabetes (Project Leonardo). Vasc Health Risk Manag 6: 297-305. 